\title{
Clinical course of asymptomatic small enhancing brain nodules in patients with nonsmall cell lung cancer: do we have to follow them up?
}

Hyun Woo Lee ${ }^{1}{ }^{1}$, Jaeyoung $\mathrm{Cho}^{2}$, Nakwon Kwak ${ }^{2}$, Inpyeong Hwang ${ }^{3}$, Young Sik Park ${ }^{2}$, Chang-Hoon Lee ${ }^{2}$, Sang-Min Lee ${ }^{2}$, Chul-Gyu Yoo ${ }^{2}$, Young Whan Kim² and Sun Mi Choi (10) ${ }^{2}$

Affiliations: ${ }^{1}$ Division of Pulmonary and Critical Care Medicine, Dept of Internal Medicine, Seoul Metropolitan Government-Seoul National University Boramae Medical Center, Seoul, South Korea. ${ }^{2}$ Division of Pulmonary and Critical Medicine, Dept of Internal Medicine, Seoul National University College of Medicine, Seoul National University Hospital, Seoul, South Korea. ${ }^{3}$ Dept of Radiology, Seoul National University Hospital, Seoul, South Korea.

Correspondence: Sun Mi Choi, Division of Pulmonary and Critical Care Medicine, Dept of Internal Medicine, Seoul National University Hospital, 101 Daehak-Ro Jongno-Gu, Seoul, 03080, Republic of Korea. E-mail: sunmich81@gmail.com

\section{ABSTRACT}

Aims: Brain magnetic resonance imaging (MRI) is recommended during the initial work-up for nonsmall cell lung cancer (NSCLC). Although small enhancing brain nodules not radiologically confirmed as metastatic lesions have often been detected, their clinical course has not been well studied.

Methods: This nested case-control study included NSCLC patients who had small enhancing brain nodules detected by serial brain MRIs from January 2014 through December 2018 at a tertiary university hospital. Small enhancing brain nodules were defined as round enhancing nodules of $\leqslant 10 \mathrm{~mm}$ diameter without oedema in thin-section $(1 \mathrm{~mm})$ contrast MRIs. The incidence, natural course and risk factors of growing nodules were evaluated.

Results: A total of 171 small enhancing brain nodules in 123 patients were observed over an average of 22.1 months. The incidence of nodule growth was $49.1 \%$ with mean growth rate of $11 \mathrm{~mm} \cdot \mathrm{year}^{-1}$. We found that $25.0 \%$ of the growing nodules contributed to clinical upstaging compared to the initial stage. Cerebral events were more common in growing nodules; therefore, local therapy was performed more often. However, there was no difference in the cerebral event-related mortality. Nodule growth was more frequent in younger individuals, multiple nodules, advanced disease, poorly differentiated carcinoma, rim enhancement and larger initial size. In multivariable analysis, predictors of growth were $\mathrm{N}$ stage $\geqslant 1$, existence of epidermal growth factor receptor mutation and larger initial size.

Conclusion: Considering the clinical course of small enhancing brain nodules, more intensive evaluation is required for early detection and pre-emptive intervention when accompanied by risk factors.

@ERSpublications

Small enhancing brain nodules are found in $4.1 \%$ of NSCLC. Growth is found in the $49.1 \%$ with a rate of $11.0 \mathrm{~mm}$ per year. Lymph node metastasis, EGFR mutation and larger diameter are risk factors for growth. https://bit.ly/2ALqhhM

Cite this article as: Lee HW, Cho J, Kwak N, et al. Clinical course of asymptomatic small enhancing brain nodules in patients with nonsmall cell lung cancer: do we have to follow them up? ERJ Open Res 2020; 6: 00109-2020 [https://doi.org/10.1183/23120541.00109-2020].

This article has supplementary material available from openres.ersjournals.com

Received: 29 Feb 2020 | Accepted after revision: 4 June 2020

Copyright $\odot$ ERS 2020. This article is open access and distributed under the terms of the Creative Commons Attribution Non-Commercial Licence 4.0. 


\section{Introduction}

Metastatic lesions are found at the time of diagnosis in about $30-40 \%$ of patients with nonsmall cell lung cancer (NSCLC) [1,2]. About 10-20\% of NSCLC patients have at least one brain metastasis at the time of diagnosis [3-5]. Metastatic brain lesion significantly increases morbidity and mortality in NSCLC [6, 7]. NSCLC patients in whom brain metastasis was detected at the time of initial diagnosis had worse survival rates than those in whom it developed later [8]. Therefore, brain magnetic resonance imaging (MRI) has been an important tool for initial diagnosis of brain metastasis in NSCLC patients [9-11].

The indication of brain MRI has been extended from patients with advanced stage or neurological symptoms to the early stage (IB) or asymptomatic patients. Silent brain metastasis has been identified in a large proportion of patients with NSCLC [12, 13]. Brain metastasis constitutes the majority of asymptomatic metastasis cases in stage I NSCLC [14]. Early detection of asymptomatic brain metastasis was related with reduced incidences of morbidity and mortality [15]. In general, the presence of neurological symptoms no longer determines the need for a brain MRI, except for stage IA NSCLC.

The increasing use of brain MRI scan for brain metastasis work-up has increased the detection of asymptomatic enhancing brain nodules. The radiological features of brain metastasis in MRIs have been well identified [16]. However, when the diameter of the enhancing brain nodule is too small, it is often difficult to radiologically distinguish malignant lesions from benign ones. In practice, instead of a brain biopsy, short-term follow-up with brain MRI is usually conducted for the undetermined brain nodules. Once a growth of the brain nodule is detected or a neurological symptom appears during the follow-up, radiation therapy or surgical intervention needs to be considered. Therefore, it is important to delineate the natural course of small enhancing brain nodules and identify risk factors for the growing nodules.

\section{Methods}

For structured and standardised reporting, we followed the statements from strengthening the reporting of observational studies in epidemiology guidelines [17].

\section{Study design and eligibility criteria}

We conducted a nested case-control study by reviewing the electronic medical records of pathologically diagnosed NSCLC patients from January 2014 through December 2018 at a tertiary teaching hospital in Korea. The inclusion criteria for the present study were as follows: 1) $\geqslant 18$ years old; 2) absence of neurological symptoms; 3) small enhancing brain nodules detected in the initial thin-section (1 $\mathrm{mm})$ brain MRI with contrast; and 4) implementation of serial brain MRIs to follow-up the small enhancing brain nodules for at least 3 months. We excluded patients who started any treatment likely to affect the size of the small enhancing brain nodules at initial presentation (i.e. a definite local therapy (surgical or radiation therapy) or a tyrosine kinase inhibitor therapy with the potential to penetrate the blood-brain barrier, such as afatinib, alectinib, brigatinib, crizotinib, dacomitinib, erlotinib, gefitinib, lorlatinib and osimertinib). If a patient had newly started one of those therapies in the middle of follow-up, we finished observation at the start of treatment and excluded the impact of the therapy on the growth rate of the initially observed nodule. Additionally, patients diagnosed with a primary brain tumour were excluded.

\section{Clinical and radiological assessments}

We evaluated clinical characteristics, including age, sex, history of smoking cigarettes (in pack-years), use of systemic chemotherapy, interval and frequency of brain MRIs during the observed period, total observed duration, and tumour-node-metastasis (TNM) stage. We assessed the histological features, including pathological diagnosis, epidermal growth factor receptor (EGFR) mutation, anaplastic lymphoma kinase (ALK) rearrangement and programmed death-ligand 1 (PD-L1) expression.

We analysed the radiological features, including the location, number of concurrent brain nodules, rim enhancement, initial size and interval size change. The interval of follow-up brain MRI was determined by each clinician. The small enhancing brain nodule was defined as an enhancing round nodule $\leqslant 10 \mathrm{~mm}$ diameter without oedema or haemorrhage. Brain nodules were primarily identified in formal brain MRI scan reports, and each MRI image was reviewed to identify small enhancing brain nodules. Also, the follow-up brain MRI images were reviewed to trace radiological changes in small enhancing brain nodules. These radiological features and interval size changes were determined after discussing with an experienced brain radiologist $(\mathrm{IH})$. Based on the follow-up MRI results, the brain nodules were classified into those with growth and without growth. Growth was defined as a radiological evidence of increased diameter of the brain nodules in follow-up brain MRI. No growth was defined as no radiological evidence of increased diameter of the brain nodules in follow-up brain MRI at 6 months or more. Baseline characteristics and clinical and radiological features were compared between brain nodules with growth and without growth to find risk factors that were significantly related with growth of the brain nodule. 
Our primary end-point was to analyse the incidence rate of growing nodules among the small enhancing brain nodules. The small enhancing brain nodules were observed until death or initiation of any treatment affecting the growth rate. To reveal the natural course of growing nodules, we evaluated interval change of the diameter $\left(\mathrm{mm}, \mathrm{mm} \cdot \mathrm{year}^{-1}\right)$, the event of newly developed neurological symptom or sign, the event of definite local therapy (surgical resection, stereotactic radiosurgery or whole-brain radiotherapy) for the newly developed neurological symptom or sign, and the event of central nervous system (CNS)-related death or all-cause death. We estimated the actual impact of growing brain nodules on clinical decisions by identifying events of clinical upstaging or treatment plan change, such as local to systemic therapy or curative to palliative therapy, via review of medical records. Subgroup analysis was performed to know how growth rate or growth risk was different according to significant radiological features.

\section{Brain MRI protocol}

Brain MRI scans were performed using a 3T magnetic resonance scanner (Ingenia, Philips Healthcare, Best, the Netherlands) with a 32-channel head coil. In addition to routine pre-contrast brain magnetic resonance sequences, thin-section post-contrast images were obtained after intravenously administering gadobutrol (Gadovist; Bayer Schering Pharma, Berlin, Germany) at a dose of $0.1 \mathrm{mmol} \cdot \mathrm{kg}^{-1}$ of body weight. The post-contrast study included sagittal T1-weighted three-dimensional gradient-echo sequence (repetition time (TR) of $8.5 \mathrm{~ms}$; echo time (TE) of $4.6 \mathrm{~ms}$; flip angle (FA) of $8^{\circ}$; field of view (FOV) of $240 \times 240 \mathrm{~mm}$; matrix of $240 \times 240$; one excitation; and slice thickness of $1 \mathrm{~mm}$ ). In addition, sagittal T1-weighted three-dimensional turbo spin-echo sequence with motion-sensitised driven-equilibrium preparation (TR of $500 \mathrm{~ms}$; TE of $28.9 \mathrm{~ms}$; FA of $90^{\circ}$; FOV of $240 \times 240 \mathrm{~mm}$; matrix of $240 \times 240$; one excitation; and slice thickness of $1 \mathrm{~mm}$ ) was obtained for better detection of tiny enhancing nodules by selective suppression of blood vessel signals [18].

\section{Statistical analyses}

Comparative analyses of categorical variables were performed using Pearson's Chi-squared test or Fisher's exact test. Continuous variables were analysed using the t-test and median and interquartile range (IQR) or mean and SD were calculated. The time to growth of the small enhancing brain nodule was analysed using Cox proportional hazard regression model. After examining multicollinearity, multivariable analyses were performed using variables related to the growth of small enhancing brain nodules. Missing data on molecular testing were handled by excluding the patients in our analysis and addressed in the footnotes of each table. All statistical analyses were done using R statistical software, version 3.5.1 (R Core Team, 2018, Vienna, Austria).

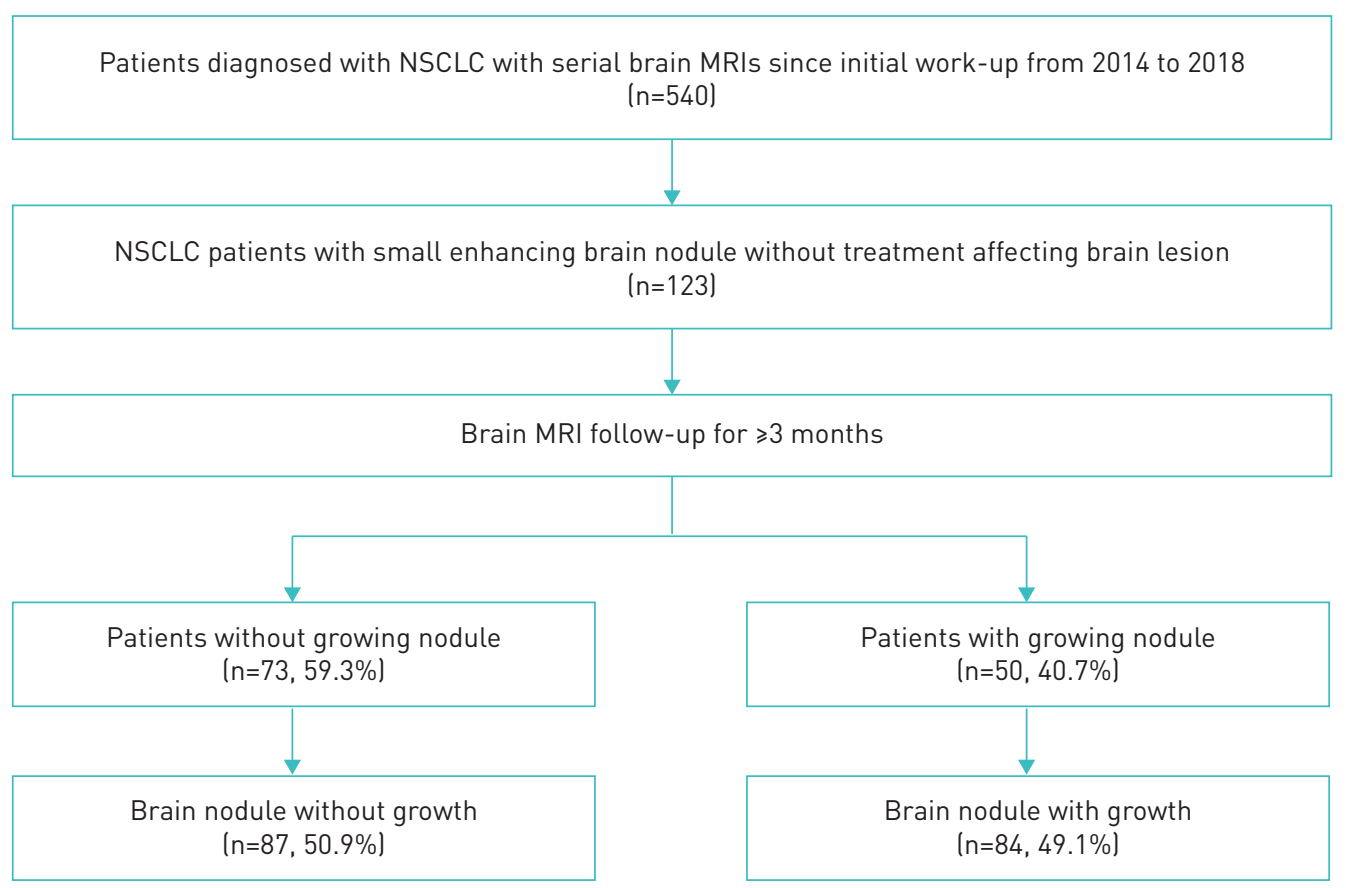

FIGURE 1 Flow chart of inclusion criteria for eligible small enhancing brain nodules. NSCLC: nonsmall cell lung cancer; MRI: magnetic resonance imaging. 
Ethics

The Institutional Review Board Committee of Seoul National University Hospital approved the study protocol and waived the need for obtaining informed consents to access the electronic medical records (no. H-1901-154-1006)

\section{Results}

Among a total of 2998 patients with NSCLC who were evaluated using brain MRI, 540 patients were followed-up for brain lesions using serial brain MRIs starting from the time of initial diagnosis of NSCLC. There were 123 patients with 171 small enhancing brain nodules that met our eligibility criteria. Mean

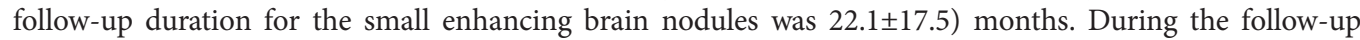
period, the estimated incidence rate of the growing small enhancing brain nodule was 84 out of 171 (49.1\%) (figure 1).

\section{Baseline characteristics of small enhancing brain nodules}

The baseline characteristics of the study population are summarised in table 1 . The mean patient age was $62.7 \pm 11.1)$ years and 114 out of $171(66.67 \%)$ small enhancing brain nodules were detected in males. During regular follow-up brain MRI scans, the small enhancing brain nodule was found growing in 50 out of 123 (40.7\%) patients. Among patients with and without evidence of a growing brain nodule, the former were more likely to be younger and to have received more systemic chemotherapy whereas a solitary lesion was more likely to be found in the latter group of patients. There were no significant differences in sex,

\section{TABLE 1 Baseline characteristics of NSCLC patients with small enhancing brain nodules}

\begin{tabular}{|c|c|c|c|}
\hline & $\begin{array}{l}\text { Patients without growing brain } \\
\text { nodule }(n=73)\end{array}$ & $\begin{array}{l}\text { Patients with growing brain } \\
\text { nodule }(n=50)\end{array}$ & p-value \\
\hline Age years & $64.7 \pm 10.5$ & $60.4 \pm 11.4$ & 0.034 \\
\hline Sex male & $49(67.1 \%)$ & $34(68.0 \%)$ & 1.000 \\
\hline \multicolumn{4}{|l|}{ Smoking history } \\
\hline Never & $24(32.9 \%)$ & $17(34.0 \%)$ & 1.000 \\
\hline Current & $15(20.5 \%)$ & $14(28.0 \%)$ & 0.459 \\
\hline Ex-smoker & $34(46.6 \%)$ & $19(38.0 \%)$ & 0.449 \\
\hline Pack-years & $24.2 \pm 25.4$ & $21.1 \pm 23.3$ & 0.494 \\
\hline \multicolumn{4}{|l|}{ TNM stage of NSCLC } \\
\hline \multicolumn{4}{|l|}{ T stage } \\
\hline $\mathrm{T} 1$ & $26(35.6 \%)$ & $11(22.0 \%)$ & 0.156 \\
\hline T2 & $28(38.4 \%)$ & $24(48.0 \%)$ & 0.380 \\
\hline T3 & $13(17.8 \%)$ & $8(16.0 \%)$ & 0.986 \\
\hline T4 & $6(8.2 \%)$ & $7(14.0 \%)$ & 0.468 \\
\hline \multicolumn{4}{|l|}{$\mathrm{N}$ stage } \\
\hline No & $33(45.2 \%)$ & $13(26.0 \%)$ & 0.049 \\
\hline N1 & $9(12.3 \%)$ & $5(10.0 \%)$ & 0.912 \\
\hline N2 & $16(21.9 \%)$ & $15(30.0 \%)$ & 0.422 \\
\hline N3 & $15(20.5 \%)$ & $17(34.0 \%)$ & 0.144 \\
\hline \multicolumn{4}{|l|}{ Extracranial TNM stage } \\
\hline Stage I & $20(27.4 \%)$ & $5(10.0 \%)$ & 0.033 \\
\hline Stage II & $13(17.8 \%)$ & $2(4.0 \%)$ & 0.044 \\
\hline Stage III & $21(28.8 \%)$ & $11(22.0 \%)$ & 0.528 \\
\hline Stage IV & $19(26.0 \%)$ & $32(64.0 \%)$ & $<0.001$ \\
\hline \multicolumn{4}{|l|}{ Treatment } \\
\hline CCRT & $13(17.8 \%)$ & $3(6.0 \%)$ & 0.101 \\
\hline Systemic chemotherapy & $46(63.0 \%)$ & $42(84.0 \%)$ & 0.020 \\
\hline Number of brain nodules & & & $<0.001$ \\
\hline 1 & $48(55.2 \%)$ & $18(21.4 \%)$ & \\
\hline 2 & $29(33.3 \%)$ & $24(28.6 \%)$ & \\
\hline$\geqslant 3$ & $10(11.5 \%)$ & $42(50.0 \%)$ & \\
\hline $\begin{array}{l}\text { Total follow-up duration } \\
\text { months }\end{array}$ & $24.8 \pm 18.8$ & $21.4 \pm 17.5$ & 0.316 \\
\hline
\end{tabular}

Continuous variables are expressed as mean \pm SD and categorical variables are expressed as the number of patients (percentage). NSCLC: nonsmall cell lung cancer; TNM: tumour, node, metastasis; CCRT: concurrent chemoradiation therapy. 
smoking history or total observed duration between these two groups. Also, multiple lesions $(\geqslant 3)$ were significantly related with brain nodule growth.

\section{Clinical and radiological manifestations of small enhancing brain nodules}

We examined the difference in TNM staging between patients with and without growing small enhancing brain nodules (table 1). The $\mathrm{T}$ stage was not related with the growth of brain nodules, nor did the $\mathrm{N}$ stage affect their growth. Lymph node involvement was significantly associated with a higher detection rate of brain nodule growth. The small enhancing brain nodules were more likely to be stable in case of extracranial TNM stage I and II, but grew in extracranial metastatic lesions (TNM stage IV). Also, we evaluated whether the histological features of NSCLC were related to the growth of small enhancing brain nodules (table 2). Adenocarcinoma was the most common histological type (62.6\%) among the various pathologic features of NSCLC. There was no difference in the proportion of adenocarcinoma, squamous carcinoma and large-cell carcinoma between small enhancing brain nodules with and without growth. EGFR mutation, ALK rearrangement and PD-L1 expression were not significantly associated with brain nodule growth detection.

Radiological features of small enhancing brain nodules are described in table 3 . There was no differences in geographical distribution throughout the brain according to the growth of the brain nodules. Growing brain nodules had a greater diameter at initial presentation $(4.0 \mathrm{~mm}$ versus $2.5 \mathrm{~mm}, \mathrm{p}<0.001)$ and the nodules with rim enhancement were more likely to be growing $(\mathrm{p}<0.001)$. Although the MRI interval was similar, MRI scans were conducted less often in patients with a brain nodule with growth.

\section{Natural history of small enhancing brain nodules with growth}

In growing small enhancing brain nodules $(\mathrm{n}=84)$, median change of diameter was $3.2 \mathrm{~mm}$ (IQR, 2.0-7.8) and annual median growth rate was $11.0 \mathrm{~mm} \cdot \mathrm{year}^{-1}$ (IQR, 4.9-20.7; table 4 and figure 2). We found that $25 \%$ of the growing brain nodules contributed to clinical upstaging of NSCLC. In about $35 \%$ of the growing brain nodules, the chemotherapy regimen was changed immediately after the detection of brain nodule growth. More CNS-related events and definite local therapy were observed in small enhancing brain nodules with growth $(\mathrm{p}=0.001$ and $\mathrm{p}=0.003$, respectively). For the patients with definite local therapy, the protocolised radiation doses of $20 \mathrm{~Gy}$ in 5 fractions or $30 \mathrm{~Gy}$ in 10 fractions were applied for whole-brain radiotherapy and the median peripheral dose of $22 \mathrm{~Gy}$ (range, 15-25 Gy) was prescribed at the median 50\% isodose line for Gamma Knife radiosurgery (Leksell Gamma Knife Icon $^{\mathrm{TM}}$ ). Brain nodules with growth were significantly associated with a higher overall mortality rate when compared with those without growth $(\mathrm{p}=0.001)$. However, the relationship between growth of small enhancing brain nodules and CNS-related mortality was not significant $(\mathrm{p}=0.638)$.

In subgroup analyses, the small enhancing brain nodules with rim enhancement showed a higher growth rate $\left(17.7 \mathrm{~mm} \cdot\right.$ year $^{-1}$ versus $\left.5.6 \mathrm{~mm} \cdot \mathrm{year}^{-1}, \mathrm{p}<0.001\right)$ (supplementary information 1 ). In addition, we

\begin{tabular}{|c|c|c|c|}
\hline & $\begin{array}{l}\text { Brain nodule without growth } \\
\qquad(\mathrm{n}=87)\end{array}$ & $\begin{array}{l}\text { Brain nodule with growth } \\
\qquad(\mathrm{n}=84)\end{array}$ & p-value \\
\hline \multicolumn{4}{|l|}{ Histology of NSCLC } \\
\hline Adenocarcinoma & $54(62.1 \%)$ & $53(63.1 \%)$ & 1.000 \\
\hline Squamous carcinoma & $21(24.1 \%)$ & $12(14.3 \%)$ & 0.168 \\
\hline Large-cell carcinoma & $5(5.7 \%)$ & $3(3.6 \%)$ & 0.717 \\
\hline NSCLC, others & $2(2.3 \%)$ & 0 & 0.477 \\
\hline PD carcinoma & $5(5.7 \%)$ & $16(19.0 \%)$ & 0.019 \\
\hline EGFR mutation ${ }^{\#}$ & $21(33.3 \%)$ & $24(41.4 \%)$ & 0.467 \\
\hline$A L K$ rearrangement ${ }^{\Uparrow}$ & $2(3.4 \%)$ & $4(6.3 \%)$ & 0.753 \\
\hline PDL-1 expression ${ }^{+}$ & $23(46.9 \%)$ & $15(32.6 \%)$ & 0.224 \\
\hline
\end{tabular}

Variables are expressed as the number of patients (percentage). NSCLC: nonsmall cell lung cancer; PD: poorly differentiated; EGFR: epidermal growth factor receptor; ALK: anaplastic lymphoma kinase; PD-L1: programmed death-ligand 1. " : EGFR mutation was analysed by real-time PCR in 121 cases; ": ALK rearrangement was analysed by immunohistochemistry $(>10 \%)$ and confirmed by fluorescence in situ hybridisation in 121 cases; $^{+}$: PD-L1 expression was analysed by immunohistochemistry (>10\%) in 95 cases. 


\begin{tabular}{|c|c|c|c|}
\hline & $\begin{array}{l}\text { Brain nodule without } \\
\text { growth ( } n=87 \text { ) }\end{array}$ & $\begin{array}{l}\text { Brain nodule with growth } \\
\qquad(n=84)\end{array}$ & p-value \\
\hline \multicolumn{4}{|c|}{ Radiological features of brain nodule } \\
\hline Location & & & 0.300 \\
\hline Cerebellum & $8(9.2 \%)$ & $13(15.5 \%)$ & \\
\hline Frontal lobe & $28(32.2 \%)$ & $17(20.2 \%)$ & \\
\hline Occipital lobe & $12(13.8 \%)$ & $15(17.9 \%)$ & \\
\hline Parietal lobe & $19(21.8 \%)$ & $23(27.4 \%)$ & \\
\hline Temporal lobe & $9(10.3 \%)$ & $10(11.9 \%)$ & \\
\hline Others & $11(12.6 \%)$ & $6(7.1 \%)$ & \\
\hline Rim enhancement & $8(9.2 \%)$ & $34(40.5 \%)$ & $<0.001$ \\
\hline Initial diameter $\mathrm{mm}$ & $2.5 \pm 1.4$ & $4.0 \pm 2.1$ & $<0.001$ \\
\hline MRI interval months & $6.0 \pm 6.0$ & $5.5 \pm 5.4$ & 0.419 \\
\hline $\begin{array}{l}\text { Frequency of MRI during } \\
\text { observed period }\end{array}$ & $2.9 \pm 1.9$ & $2.5 \pm 0.8$ & 0.049 \\
\hline
\end{tabular}

found a higher risk of growth in brain nodules with a diameter $\geqslant 3 \mathrm{~mm}$, especially when observed for 6 months or longer (supplementary information 2 and 3).

Analysis of risk factors related to the growth of small enhancing brain nodule In univariable analysis using Cox regression hazard model, we found that $\mathrm{N}$ stage $\geqslant 1$, extracranial metastasis, EGFR mutation, PD-L1 expression $>10 \%$, number of brain nodules, rim enhancement and initial size were significantly related with growth of small enhancing brain nodules upon observed time (table 5). In multivariable analysis, $\mathrm{N}$ stage $\geqslant 1$, existence of EGFR mutation and a larger initial size were significantly associated with a higher risk of growth of small enhancing brain nodules upon observed time.

\section{Discussion}

This is a large cohort of very small brain nodules not deemed to be metastases at baseline work-up of newly diagnosed lung cancer. Predictors we found in patients with nodules showing growth during follow-up were also features of a more aggressive phenotype such as younger age, a histology of poorly differentiated carcinoma, higher extracranial TNM stage, multiple brain nodules and more systemic

\section{TABLE 4 Natural course of the small enhancing brain nodule over the period of follow-up}

\begin{tabular}{lccc} 
& $\begin{array}{c}\text { Brain nodule without } \\
\text { growth (n=87) }\end{array}$ & $\begin{array}{c}\text { Brain nodule with } \\
\text { growth (n=84) }\end{array}$ & p-value \\
\hline $\begin{array}{l}\text { Change of diameter, mm } \\
\text { Change of diameter per year, mm.year }{ }^{-1}\end{array}$ & - & $3.2(2.0-7.8)$ & - \\
$\begin{array}{l}\text { Clinical upstaging due to brain nodule } \\
\text { growth }\end{array}$ & - & $11.0(4.9-20.7)$ & - \\
$\begin{array}{l}\text { Chemotherapy regimen change due to } \\
\quad \text { detection of brain nodule growth }\end{array}$ & - & $21(25.0 \%)$ & - \\
$\begin{array}{l}\text { CNS-related event } \\
\text { Definite local therapy }\end{array}$ & & $29(34.5 \%)$ & - \\
$\begin{array}{l}\text { CNS-related mortality } \\
\text { All-cause mortality }\end{array}$ & $18(20.7 \%)$ & $38(45.2 \%)$ & 0.001 \\
& $26(29.9 \%)$ & $45(53.6 \%)$ & 0.003 \\
& $3(3.4 \%)$ & $1(1.2 \%)$ & 0.638 \\
\end{tabular}

Continuous variables are expressed as median (interquartile range) and the categorical variables are expressed as the number of patients (percentage). CNS: central nervous system. \#: Definite local therapy includes surgical resection, stereotactic radiosurgery and whole-brain radiotherapy. Definite local therapy was not only for initial small enhancing brain nodule with growth, but also for newly developed other brain metastases and their complications. 


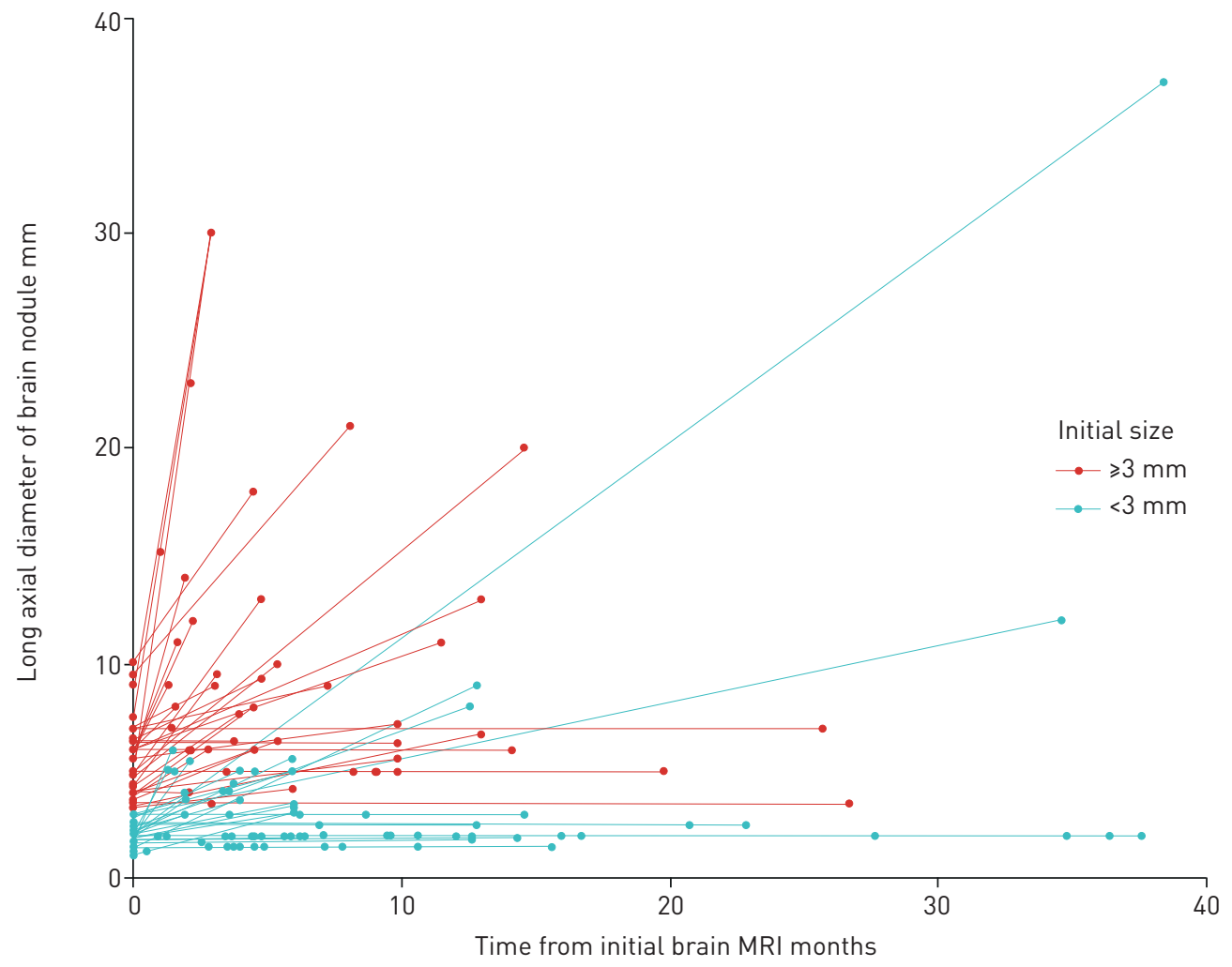

FIGURE 2 Natural course of small enhancing brain nodules. Green line indicates the small enhancing brain nodules with initial diameter of $<3 \mathrm{~mm}$ and red line indicates the small enhancing brain nodules with initial diameter of $\geqslant 3 \mathrm{~mm}$. GGN: ground-glass nodule.

chemotherapy. Regular brain MRIs with at least 6-month intervals were considered adequate in that the cumulative growth rate of the growing small enhancing brain nodules was $11.0 \mathrm{~mm} \cdot \mathrm{year}^{-1}$ in diameter. The growth has a clinical significance because about $25 \%$ of these nodules contributed to clinical upstaging and about $35 \%$ of them contributed to change of chemotherapy regimen in our study. Closer follow-up with frequent brain MRI scans or pre-emptive therapy might be needed in NSCLC patients with any lymph node metastasis, EGFR mutation or a larger diameter $(\geqslant 3 \mathrm{~mm})$ of the brain nodule, given the increased hazard ratio of growth upon observed time among the small enhancing brain nodules in these patients.

Brain MRI scan has played an important role in the initial work-up for staging of NSCLC. A previous study reported that $22.4 \%$ of brain metastases were present in the initial brain MRI [19]. Initial brain MRIs detected metastatic lesions in about $5 \%$ of the patients with squamous cell carcinoma and in about $16 \%$ of those with adenocarcinoma $[20,21]$. An important point in our study is that in about $4 \%$ of the NSCLC patients, additional small enhancing nodules were detected that were insufficient to make a definite diagnosis of a metastatic lesion. About half of the small enhancing brain nodules were eventually found growing during the 22-month follow-up period. When brain MRI was repeated every 5.5 months, about $94 \%$ of the growth of brain nodule could be detected within 12 months. Our study provides a perspective for future studies regarding follow-up strategies in NSCLC patients when a small enhancing brain nodule is found.

Another important finding of our study was that the growing small enhancing brain nodules derived more CNS-related events but did not increase CNS-related mortality. This finding may be explained by a higher rate of definite local therapy in this group which prevents the progression of the metastatic lesion. In fact, a higher overall mortality rate in patients with growing small enhancing brain nodules was likely not caused by the brain lesion itself, but may be attributable to their advanced TNM stage. In current practices with short-term brain MRI follow-up and definite local therapy for a growing brain nodule, detection of small enhancing brain nodules seems to have limited impact on patient's prognosis. However, a shorter follow-up interval can be beneficial because an earlier intervention in high-risk patients may be likely to reduce CNS-related symptoms [22]. 


\begin{tabular}{|c|c|c|c|c|c|c|}
\hline & \multicolumn{3}{|c|}{ Univariable analysis } & \multicolumn{3}{|c|}{ Multivariable analysis } \\
\hline & $\begin{array}{l}\text { Hazard } \\
\text { ratio }\end{array}$ & $95 \% \mathrm{Cl}$ & p-value & $\begin{array}{l}\text { Hazard } \\
\text { ratio }\end{array}$ & $95 \% \mathrm{Cl}$ & p-value \\
\hline Age & 0.984 & $0.967-1.002$ & 0.078 & 0.988 & $0.929-1.051$ & 0.709 \\
\hline Sex male & 0.817 & $0.518-1.290$ & 0.386 & - & - & - \\
\hline Current smoker & 0.745 & $0.419-1.324$ & 0.315 & - & - & - \\
\hline Pack-year & 0.991 & $0.981-1.002$ & 0.097 & 1.022 & $0.999-1.047$ & 0.064 \\
\hline$N$ stage $\geqslant 1$ & 1.992 & $1.192-3.322$ & 0.009 & 3.472 & $1.160-10.417$ & 0.026 \\
\hline Extracranial stage IV & 3.760 & $2.249-6.287$ & $<0.001$ & 2.904 & $0.918-9.190$ & 0.070 \\
\hline Adenocarcinoma & 0.939 & $0.600-1.470$ & 0.783 & - & - & - \\
\hline Squamous carcinoma & 1.195 & $0.643-2.222$ & 0.574 & - & - & - \\
\hline Large-cell carcinoma & 0.640 & $0.201-2.039$ & 0.450 & - & - & - \\
\hline $\begin{array}{l}\text { Poorly differentiated } \\
\text { carcinoma }\end{array}$ & 1.265 & $0.731-2.191$ & 0.401 & - & - & - \\
\hline EGFR mutation & 1.736 & $1.021-2.954$ & 0.042 & 5.670 & $1.996-16.104$ & 0.001 \\
\hline$A L K$ amplification & 1.230 & $0.444-3.410$ & 0.690 & - & - & - \\
\hline PD-L1 expression $>10 \%$ & 0.474 & $0.250-0.898$ & 0.022 & 0.658 & $0.257-1.686$ & 0.384 \\
\hline CCRT & 0.323 & $0.102-1.022$ & 0.055 & - & - & - \\
\hline $\begin{array}{l}\text { Conventional } \\
\text { chemotherapy }\end{array}$ & 1.507 & $0.848-2.680$ & 0.163 & - & - & - \\
\hline Single lesion & 0.368 & $0.217-0.624$ & $<0.001$ & 0.358 & $0.108-1.179$ & 0.091 \\
\hline Rim enhancement & 2.668 & $1.707-4.171$ & $<0.001$ & 1.868 & $0.768-4.542$ & 0.168 \\
\hline Initial size $\mathrm{mm}$ & 1.215 & $1.106-1.334$ & $<0.001$ & 1.436 & $1.170-1.763$ & $<0.001$ \\
\hline \multicolumn{7}{|c|}{$\begin{array}{l}\text { Multivariable analysis was conducted with the variables with } p<0.1 \text { in the univariable analyses. EGFR: } \\
\text { epidermal growth factor receptor; ALK: anaplastic lymphoma kinase; PD-L1: programmed death-ligand } 1 \text {; } \\
\text { CCRT: concurrent chemoradiation therapy. }\end{array}$} \\
\hline
\end{tabular}

We found that the growth rate of small enhancing brain nodules was significantly associated with their initial size and rim enhancement. The initial diameter of the nodules not only predicted the growth, but also the magnitude of growth (i.e. a larger diameter was associated with a greater growth rate, whereas rim enhancement did not show significant power in the multivariable analysis to predict the growth of small enhancing brain nodules). In fact, brain metastasis accounts for only $30 \%$ of the radiologically rim-enhancing lesions [23]. Furthermore, our study showed that the growth rate is greater with rim enhancement in growing small enhancing brain nodules. Therefore, it would be more reasonable to differentiate the brain MRI follow-up interval for small enhancing brain nodules according to the diameter and rim enhancement in the initial brain MRI.

Our study has several limitations. First, we excluded enhancing brain lesions that were diagnosed and treated as definite brain metastases at the initial work-up for NSCLC staging. The natural course of the growing small enhancing brain nodules included in our study cannot be applied to all the metastatic brain lesions in NSCLC, because it would be less aggressive. Second, brain biopsy was not conducted for any patient to diagnose brain metastasis at initial work-up. Growth is not synonymous with metastasis. It is possible to incidentally find growing enhancing brain nodules in primary brain tumours or infections [24]. However, given the clinical context that brain MRI was performed for staging work-up of NSCLC, most growths were likely to suggest metastasis. For small enhancing brain nodules that did not grow, it is difficult to make the final diagnosis as one disease entity. Vascular enhancement and capillary telangiectasia are commonly considered as a radiological diagnosis in these cases. Stable or slowly growing metastatic lesions may also be included in no growth group without detectable growth during our study period. However, stable or slowly growing metastasis is considered as a very rare case and does not demonstrate clinical significance. A long-term follow-up for slowly growing metastasis may be needed, as the life expectancy of NSCLC patients has improved. Third, the frequency of follow-up brain MRI was lower in small enhancing brain nodules with growth during the observed period. When the growth of brain nodule was identified, the observed duration was censored because the treatment for the brain lesion was initiated immediately. In fact, the growing brain nodule had a shorter observation period of about 3.4 months. However, there was no difference in brain MRI intervals between patients having brain nodules with and without growth groups. The physician's practice appears similar among the patients with small enhancing brain nodules. 


\section{Conclusions}

A closer observation is required to detect small enhancing brain nodule during initial work-up for NSCLC staging in cases with advanced stage tumour, EGFR mutation, and initial nodule size $\geqslant 3 \mathrm{~mm}$. This may lead to earlier detection of brain metastasis and pre-emptive intervention. Further research is needed to reach a consensus on the interval and duration of performing brain MRIs in NSCLC patients with small enhancing brain nodules.

Conflict of interest: None declared.

\section{References}

1 Little AG, Gay EG, Gaspar LE, et al. National survey of non-small cell lung cancer in the United States: epidemiology, pathology and patterns of care. Lung Cancer 2007; 57: 253-260.

2 Matsuda A, Matsuda T, Shibata A, et al. Cancer incidence and incidence rates in Japan in 2008: a study of 25 population-based cancer registries for the monitoring of cancer incidence in Japan (MCIJ) project. Jpn J Clin Oncol 2014; 44: 388-396.

3 Waqar SN, Samson PP, Robinson CG, et al. Non-small-cell lung cancer with brain metastasis at presentation. Clin Lung Cancer 2018; 19: e373-e379.

4 Barnholtz-Sloan JS, Sloan AE, Davis FG, et al. Incidence proportions of brain metastases in patients diagnosed (1973 to 2001) in the Metropolitan Detroit Cancer Surveillance System. J Clin Oncol 2004; 22: 2865-2872.

5 Schouten LJ, Rutten J, Huveneers HA, et al. Incidence of brain metastases in a cohort of patients with carcinoma of the breast, colon, kidney, and lung and melanoma. Cancer 2002; 94: 2698-2705.

6 Aoyama H, Shirato H, Tago M, et al. Stereotactic radiosurgery plus whole-brain radiation therapy vs stereotactic radiosurgery alone for treatment of brain metastases: a randomized controlled trial. JAMA 2006; 295: 2483-2491.

7 Kocher M, Soffietti R, Abacioglu U, et al. Adjuvant whole-brain radiotherapy versus observation after radiosurgery or surgical resection of one to three cerebral metastases: results of the EORTC 22952-26001 study. J Clin Oncol 2011; 29: 134-141.

8 Ali A, Goffin JR, Arnold A, et al. Survival of patients with non-small-cell lung cancer after a diagnosis of brain metastases. Curr Oncol 2013; 20: e300-e306.

9 Baldwin DR, White B, Schmidt-Hansen M, et al. Diagnosis and treatment of lung cancer: summary of updated NICE guidance. BMJ 2011; 342: d2110.

10 Novello S, Barlesi F, Califano R, et al. Metastatic non-small-cell lung cancer: ESMO Clinical Practice Guidelines for diagnosis, treatment and follow-up. Ann Oncol 2016; 27: suppl. 5, v1-v27.

11 National Comprehensive Cancer Network. Non-small cell lung cancer (version 3.2019). www.nccn.org/ professionals/physician gls/pdf/nscl.pdf Date last accessed: March 12, 2019. Date last updated: June 15, 2020.

12 Gavrilovic IT, Posner JB. Brain metastases: epidemiology and pathophysiology. J Neurooncol 2005; 75: 5-14.

13 Escuin JS dC, Menna DM, Gonzalez MA, et al. Silent brain metastasis in the initial staging of lung cancer: evaluation by computed tomography and magnetic resonance imaging. Arch Bronconeumol 2007; 43: 386-391.

14 Tanaka K, Kubota K, Kodama T, et al. Extrathoracic staging is not necessary for non-small-cell lung cancer with clinical stage T1-2 N0. Ann Thorac Surg 1999; 68: 1039-1042.

15 Sanchez de Cos J, Sojo Gonzalez MA, Montero MV, et al. Non-small cell lung cancer and silent brain metastasis. Survival and prognostic factors. Lung Cancer 2009; 63: 140-145.

16 Fink KR, Fink JR. Imaging of brain metastases. Surg Neurol Int 2013; 4: Suppl. 4, S209-S219.

17 von Elm E, Altman DG, Egger M, et al. The strengthening the reporting of observational studies in epidemiology (STROBE) statement: guidelines for reporting observational studies. J Clin Epidemiol 2008; 61: 344-349.

18 Suh CH, Jung SC, Kim KW, et al. The detectability of brain metastases using contrast-enhanced spin-echo or gradient-echo images: a systematic review and meta-analysis. J Neurooncol 2016; 129: 363-371.

19 Shi AA, Digumarthy SR, Temel JS, et al. Does initial staging or tumor histology better identify asymptomatic brain metastases in patients with non-small cell lung cancer? J Thorac Oncol 2006; 1: 205-210.

20 Lee $\mathrm{H}$, Jeong $\mathrm{SH}$, Jeong $\mathrm{BH}$, et al. Incidence of brain metastasis at the initial diagnosis of lung squamous cell carcinoma on the basis of stage, excluding brain metastasis. J Thorac Oncol 2016; 11: 426-431.

21 Yang B, Lee H, Um SW, et al. Incidence of brain metastasis in lung adenocarcinoma at initial diagnosis on the basis of stage and genetic alterations. Lung Cancer 2019; 129: 28-34.

22 Yoo H, Nam BH, Yang HS, et al. Growth rates of metastatic brain tumors in nonsmall cell lung cancer. Cancer 2008; 113: 1043-1047.

23 Schwartz KM, Erickson BJ, Lucchinetti C. Pattern of T2 hypointensity associated with ring-enhancing brain lesions can help to differentiate pathology. Neuroradiology 2006; 48: 143-149.

24 Cunliffe CH, Fischer I, Monoky D, et al. Intracranial lesions mimicking neoplasms. Arch Pathol Lab Med 2009; 133: 101-123. 